\title{
Abnormalities of age-related T cell senescence in Parkinson's disease
}

\author{
C. H. Williams-Gray ${ }^{1 *}$ (D, R. S. Wijeyekoon ${ }^{1}$, K. M. Scott ${ }^{1}$, S. Hayat ${ }^{1}$, R. A. Barker ${ }^{1}$ and J. L. Jones ${ }^{2}$
}

\begin{abstract}
Background: A wealth of evidence implicates both central and peripheral immune changes as contributing to the pathogenesis of Parkinson's disease (PD). It is critical to better understand this aspect of PD given that it is a tractable target for disease-modifying therapy. Age-related changes are known to occur in the immune system (immunosenescence) and might be of particular relevance in PD given that its prevalence rises with increasing age. We therefore sought to investigate this with respect to T cell replicative senescence, a key immune component of human ageing.

Methods: Peripheral blood mononuclear cells were extracted from blood samples from 41 patients with mild PD (Hoehn and Yahr stages 1-2, mean (SD) disease duration 4.3 (1.2) years) and 41 age- and gender-matched controls. Immunophenotyping was performed with flow cytometry using markers of $\mathrm{T}$ lymphocyte activation and senescence (CD3, CD4, CD8, HLA-DR, CD38, CD28, CCR7, CD45RA, CD57, CD31). Cytomegalovirus (CMV) serology was measured given its proposed relevance in driving $T$ cell senescence.

Results: Markers of replicative senescence in the CD8+ population were strikingly reduced in PD cases versus controls (reduced CD57 expression ( $p=0.005$ ), reduced percentage of 'late differentiated' CD57 ${ }_{\circ}$ CD28 hi cells $(p=0.007)$ and 'TEMRA' cells $(p=0.042)$ ), whilst expression of activation markers (CD28) was increased $(p=0.005)$.

This was not driven by differences in CMV seropositivity. No significant changes were observed in the CD4 population.

Conclusions: This study demonstrates for the first time that the peripheral immune profile in PD is distinctly atypical for an older population, with a lack of the CD8+ T cell replicative senescence which characterises normal ageing. This suggests that 'abnormal' immune ageing may contribute to the development of PD, and markers of $T$ cell senescence warrant further investigation as potential biomarkers in this condition.
\end{abstract}

Keywords: Parkinson's disease, Immune markers, T cells, Immunosenescence

\section{Background}

There is abundant evidence implicating a role for inflammation and immune activation in Parkinson's disease. Neuroinflammatory changes including microglial activation and increased concentrations of pro-inflammatory cytokines are well described in PD postmortem brain [1, 2], and microglial activation can be observed in vivo even in the early stages of the disease using [11C]PK-11195 PET neuroimaging [3-5]. Inflammatory cytokines including IL-6 and IL-8 are elevated in the cerebrospinal fluid (CSF) in PD compared in controls [6,7], and immune alterations have

\footnotetext{
*Correspondence: chm27@cam.ac.uk

'John Van Geest Centre for Brain Repair, Department of Clinical

Neurosciences, University of Cambridge, Forvie Site, Cambridge CB2 OPY, UK Full list of author information is available at the end of the article
}

been reported in peripheral blood including changes in monocyte [8] and lymphocyte subsets in PD $[9,10]$, which may be driven by a specific immune response to alpha synuclein [11]. Whilst such immune and inflammatory changes in PD might be, at least in part, secondary phenomena, immune manipulation in animal models of PD has been shown to alter disease susceptibility and severity $[12,13]$, suggesting that immune changes may also be a primary contributing factor to disease development. This is supported by the now well-established genetic association between the human leucocyte antigen (HLA) locus, the key genetic susceptibility factor in disorders involving pathogenic adaptive immune responses, and PD risk [14, 15]. Furthermore, our own recent data has shown that a

(c) The Author(s). 2018 Open Access This article is distributed under the terms of the Creative Commons Attribution 4.0 International License (http://creativecommons.org/licenses/by/4.0/), which permits unrestricted use, distribution, and 
pro-inflammatory cytokine profile in the serum in early PD has prognostic significance, being associated with more cognitive dysfunction and faster motor progression over 36 months of prospective follow-up in a large incident PD cohort [16].

Given that PD is a condition which becomes increasingly prevalent with age, the relevance of age-related immune dysregulation (known as immunosenescence) in this disorder warrants further investigation. One of the hallmarks of immunosenescence is the loss of naïve T cells, especially CD8+ cells, and the reciprocal accumulation of memory cells, particularly terminally differentiated effector CD8+ cells (TEMRAs), as a result of age-related thymic involution and repeated exposure to pathogens [17-19]. In vitro, progression of CD8 T cells to a senescent state is characterised by the loss of surface expression of the co-stimulatory molecule CD28 and expression of CD57 [17, 20]. In vivo, both TEMRA and CD28 ${ }_{\mathrm{lo}} \mathrm{CD} 57_{\mathrm{hi}} \mathrm{CD} 8+$ cells are increased in frequency in patients with chronic infections, e.g. HIV, as well as in older age [21-23]. Indeed, accumulation of late differentiated CD8 cells has been proposed to be a major characteristic of an immune risk profile' in patents $>85$ years which is associated with higher mortality [18, 24]. Infection with cytomegalovirus (CMV) has been proposed as the key pathogenic driver of this senescent CD8 subset [18], with $\mathrm{T}$ cell receptor (TCR) restricted, CMV-specific T cells comprising a large proportion of the CD8 T cells in the elderly $[25,26]$. Within the CD4 population, similar phenotypic changes occur with repeated antigenic stimulation, but late differentiated CD4 cells accumulate at a much lower frequency [27]. Loss of thymic $\mathrm{T}$ cell production can also be measured in the CD4 pool as a loss of CD4+ recent thymic emigrants (RTEs), CD4+ naïve cells that co-express CD31 [19].

The functional impact of $\mathrm{CD} 8+\mathrm{T}$ cell replicative senescence is an overall impairment of the adaptive immune response, with a consequent reduction in the ability to fight novel infections and impairment in responses to vaccinations in the elderly [17]. The impact of CD8+ cell senescence on the development and progression of PD is unknown. Such changes may reduce responses to disease-related antigens such as misfolded alpha synuclein, thus limiting clearance of toxic proteins and potentially contributing to PD. Alternatively, they may be protective through reducing the capacity of the immune system to become activated, hence limiting an important driver of central neuroinflammation [28]. Here, we sought to answer this question by investigating whether there was an association between an immunosenescent $\mathrm{T}$ cell phenotype and PD and to determine the relevance of CMV infection to this.

\section{Methods \\ Subjects}

Patients with early-stage PD (Hoehn and Yahr stage $\leq 2$, no dementia) were recruited from the Parkinson's Disease Research Clinic at the John Van Geest Centre for Brain Repair in Cambridge. All patients met the UKPDS Brain Bank criteria for the diagnosis of PD [29] and were aged between 55 and 80 . Controls without neurological disease were recruited from the NIHR Cambridge BioResource. MAPT (microtubule-associated protein tau) $\mathrm{H} 1 / \mathrm{H} 2$ genotypes were available for all subjects. Controls were age-, sex- and MAPT genotype-matched to patients. Exclusion criteria included current infections, chronic inflammatory or autoimmune disorders, vaccination within the past 3 weeks, surgery within the past month, and recent use of immunosuppressive therapy ( $<1$ year), oral or intravenous steroids ( $<3$ months), non-steroidal anti-inflammatories $(<2$ weeks $)$ or aspirin $>75 \mathrm{mg}(<2$ weeks). Control subjects had no history of neurological disease, no self-reported memory problems and no depression. PD cases underwent full clinical assessment including medical history and comorbidities, the Movement Disorder Society-Unified Parkinson's Disease Rating Scale (MDS-UPDRS), Hoehn and Yahr Stage, Addenbrooke's Cognitive-Examination-Revised (ACE-R), assessment of semantic fluency (animal naming in $90 \mathrm{~s}$ ) and pentagon copying and the Beck Depression Inventory. Levodopa equivalent daily doses were calculated [30]. Cases were stratified in terms of prognosis using factors identified in our previous CamPaIGN study: they were classified as high dementia risk if they carried the MAPT (microtubule-associated protein tau) $\mathrm{H} 1 / \mathrm{H} 1$ genotype and performed poorly on tests of semantic fluency $(<20$ animals in $90 \mathrm{~s})$ and/or pentagon copying $(<2 / 2)$, intermediate risk if they carried one of these factors and low risk if they carried no risk factors [31].

\section{Sample processing}

Up to $50 \mathrm{ml}$ of venous blood was collected from each participant in a combination of lithium heparin tubes for peripheral blood mononuclear cell (PBMC) isolation, plain tubes for serum separation and ethylenediaminetetraacetic acid (EDTA) tubes for measurement of full blood count and differential count. Samples for patient-control pairs were collected on the same day (9$11 \mathrm{am})$ and processed in parallel to minimise inter-assay variability. Plain tubes were left to clot for $15 \mathrm{~min}$ before centrifugation at $2000 \mathrm{rpm}$ and removal of serum, which was stored at $-80{ }^{\circ} \mathrm{C}$ prior to subsequent analysis for CMV IgG using a LIAISON ${ }^{\circ}$ CMV IgG II chemiluminescent immunoassay (DiaSorin, Italy). PBMCs were separated by centrifugation over a Ficoll gradient and washed and divided into aliquots for immunophenotyping and cell separation into $\mathrm{T}$ cell subsets. 
PBMCs for phenotyping were blocked with $2 \%$ mouse serum prior to labelling with two panels of fluorochrome-conjugated monoclonal antibodies to $\mathrm{T}$ cell surface markers of interest [panel 1: CD3(FITC), CD4(PECy5), CD8(APCCy7), HLA-DR(V500), CD38(PE); panel 2: CD3(APC), CD4(V500), CD8(APCCy7), CD28(PECy7), CCR7(FITC), CD45RA(PECy5), CD57(PE), CD31(V450), BD Biosciences). Cells were fixed with $2 \%$ paraformaldehyde. Flow cytometry was performed on a BD Biosciences FACS CantoII with BD FACS Diva software. Isotype-matched mouse monoclonal antibodies were used where appropriate to exclude non-specific antibody binding. Unstained lymphocytes were also used as negative controls.

\section{Data analysis}

Immunophenotyping data was analysed using Flowjo. Lymphocytes were gated using forward scatter and side scatter, and single cells were identified using forward-scatter area versus width. CD4 and CD8 subsets were identified by gating on CD3-high CD4-high and CD3-high CD8-high cells respectively. Naïve, central memory, effector memory and terminally differentiated memory CD45RA+ cells (TEMRA) were identified based on CCR7 and CD45RA expression [19]. Senescent 'late differentiated' cells were defined as CD28-low CD57-high cells within the CD8 population. RTEs were identified as CD31+ cells within the CD4 naïve $(C C R 7+C D 45 R A+)$ population. Expression of markers of activation (CD28, CD38, HLA-DR) and senescence (CD57) were quantified within CD4+ and $\mathrm{CD} 8+$ populations as the ratio of median fluorescence intensity in labelled versus unlabelled lymphocytes (MFI ratio), to allow for variations in voltage between samples.

The primary statistical analyses involved comparison of $\mathrm{T}$ cell subsets (as a percentage of lymphocytes) and MFI ratios for relevant markers in $\mathrm{PD}$ cases versus matched controls using paired $t$ tests. CMV positivity in patients versus controls was compared using chi-square tests, and analyses of variance (ANOVA), including age as a covariate, were used for patient-control comparisons of T cell markers in CMV-positive and CMV-negative subgroups. Relationships between relevant markers and clinical measures of motor and cognitive functions were explored using Pearson's correlations. Statistical analysis was performed using GraphPad Prism version 6.0 and SPSS version 25 (IBM).

\section{Results}

Forty-one patients with PD and 41 age/gender-matched controls were recruited. Demographic and clinical characteristics of the subjects and CMV status are shown in Table 1. Nine PD cases were designated high dementia risk, 18 were low risk and 14 were intermediate risk. Analysis of full blood and differential counts in $n=20$
Table 1 Demographic and clinical characteristics of subjects

\begin{tabular}{llll}
\hline Variable & PD $(n=41)$ & $\begin{array}{l}\text { Controls } \\
(n=41)\end{array}$ & $p$ \\
\hline Age (years) & $68.4(6.3)$ & $68.1(5.6)$ & 0.85 \\
Gender (\% male) & 68.3 & 68.3 & 1.0 \\
Disease duration (years) & $4.3(1.2)$ & & \\
MDS-UPDRS motor score & $34.9(12.4)$ & & \\
ACE-R & $93.0(8.3)$ & & \\
Levodopa equivalent daily dose (mg) & $591.5(292.9)$ & & 0.18 \\
CMV lgG (\% positive) & 46.3 & 61.0 &
\end{tabular}

Values shown are mean (SD) unless otherwise stated. Continuous variables compared using Student's $t$ tests and categorical variables compared using chi-square tests or Fisher's exact test as appropriate

MDS-UPDRS Movement Disorder Society Unified Parkinson's Disease Rating Scale, ACE-R Addenbrooke's Cognitive Examination-Revised

PD and 20 controls revealed lower total lymphocyte counts in PD cases than controls (1.4 (0.4) versus 1.9 $\left.(0.6) \times 10^{9} / \mathrm{L} ; p=0.01\right)$ with no significant differences in monocyte or neutrophil numbers. Flow cytometric data from the full cohort indicated no difference in the CD4:CD8 ratio between PD cases and controls [3.8 (2.3) versus 3.3 (3.0); $p>0.05]$.

However, there was a reduction in the number and proportion of CD28 ${ }_{\mathrm{lo}} \mathrm{CD} 57_{\mathrm{hi}} \mathrm{CD} 8+\mathrm{T}$ cells in individuals with $\mathrm{PD}$ compared to controls, along with a marginally significant reduction in CD8+ TEMRA cells and accompanying small increase in CD8+ central memory cells (Table 2 and Fig. 1a, b). Expression of the activation markers CD38 and HLA-DR on CD8+ T cells was not different between patients and controls, but expression of CD57 was reduced and expression of CD28 was increased in PD patients (Table 3; Fig. 1c), in keeping with the CD8+ subset data (Table 3; Fig. 1c). No differences

Table 2 T lymphocyte subsets

\begin{tabular}{lllll}
\hline & Subset (\% of lymphocytes) & PD & Control & $p$ \\
\hline CD8 & Naïve & $3.4(2.3)$ & $3.1(2.4)$ & 0.511 \\
& Central memory & $1.5(1.2)$ & $1.1(0.9)$ & 0.015 \\
Effector memory & $6.6(3.6)$ & $7.2(5.0)$ & 0.516 \\
TEMRA & $6.2(6.3)$ & $9.3(7.9)$ & 0.042 \\
CD28,57 hi & $5.3(4.5)$ & $9.0(8.0)$ & $0.007^{*}$ \\
& & & & \\
CD4 Naïve & $17.5(9.0)$ & $16.0(8.2)$ & 0.406 \\
Central memory & $18.0(6.7)$ & $15.8(6.7)$ & 0.052 \\
Effector memory & $14.2(6.5)$ & $12.8(6.4)$ & 0.245 \\
TEMRA & $2.1(2.4)$ & $2.0(2.3)$ & 0.747 \\
RTE & $2.2(3.3)$ & $2.1(2.2)$ & 0.827 \\
\hline
\end{tabular}

T lymphocyte subsets are expressed as a percentage of the lymphocyte population.

TEMRA terminally differentiated effector memory CD45RA+ve cells, RTE recent thymic emigrants

${ }^{*} p$ value (from paired $t$ test) which remains $<0.05$ following Bonferroni correction for multiple testing 


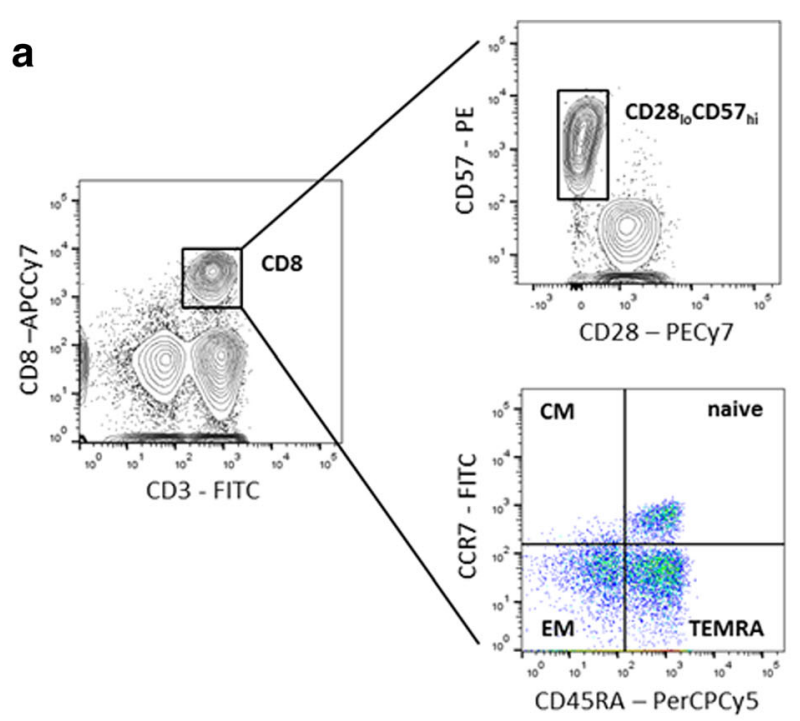

b

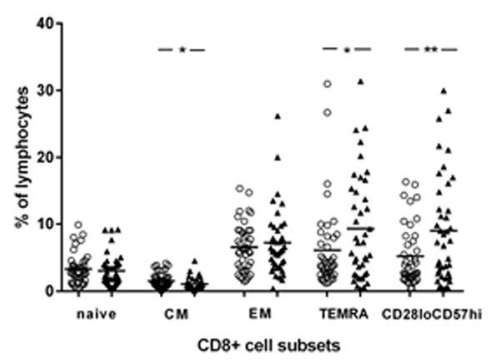

C

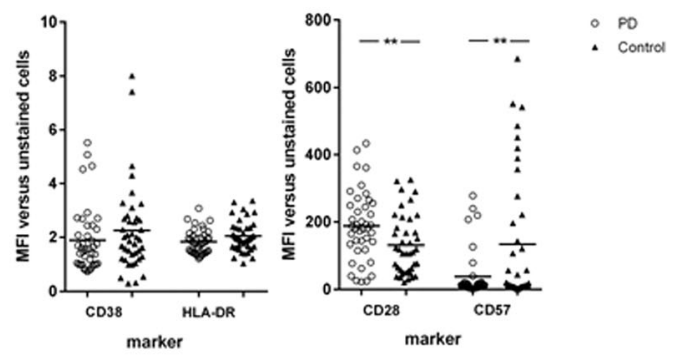

Fig. 1 CD8 immunophenotyping in PD cases $(n=41)$ versus age-matched controls $(n=41)$. a Following gating of the lymphocyte and singlet populations, CD8 cells were gated on the basis of high CD3 and CD8 staining, and the CD28 ${ }_{\circ} \mathrm{CD} 57_{\mathrm{hi}}$ subset was identified as a discrete population of CD8+ cells using 5\% contour plots. Quadrant gates were used to divide the CD8 population into naïve, central memory, effector memory and TEMRA (terminally differentiated effector memory CD45RA+ve cells) subsets on pseudocolour dot plots. b Individual-level data for CD8 cell subsets (shown as percentage of lymphocytes). c Individual-level data for surface marker expression in CD8 T cells (median fluorescence intensity (MFI) ratio versus unstained lymphocytes). Horizontal lines denote means; ${ }^{*} p<0.05,{ }^{* *} p<0.01$ in paired $t$ tests

Table 3 T cell surface marker expression

\begin{tabular}{lllll}
\hline & Marker & PD & Control & $p$ \\
\hline CD8 & CD28 & $188.6(102.5)$ & $131.5(88.3)$ & $0.005^{*}$ \\
& CD38 & $1.9(1.2)$ & $2.3(1.6)$ & 0.117 \\
& HLA-DR & $1.8(0.4)$ & $2.0(0.6)$ & 0.055 \\
& CD57 & $38.2(69.9)$ & $161.0(261.7)$ & $0.005^{*}$ \\
& & & & \\
CD4 & CD28 & $334.6(97.3)$ & $299.8(89.1)$ & 0.067 \\
& CD38 & $6.1(3.0)$ & $7.1(4.0)$ & 0.057 \\
& HLA-DR & $1.1(0.2)$ & $1.2(0.2)$ & 0.413 \\
& CD57 & $1.8(1.5)$ & $2.0(1.3)$ & 0.493
\end{tabular}

Values shown are mean (SD) ratio of median fluorescent intensity versus unstained lymphocytes (MFI ratio)

${ }^{*} p$ value which remains $<0.05$ following Bonferroni correction for multiple testing were identified in the CD4+ T cell pool between patients and controls.

For cell subsets/markers reaching significance $(p<0.05)$, ANOVA were performed to assess the effect of dementia risk group on the observed case-control differences (with 'case-control status' and 'risk subgroup' included as fixed factors and age and gender as covariates). Main effects of 'case-control status' were confirmed for the markers previously identified, but there was no interaction with risk subgroup. Amongst the PD cases, no significant correlations were found between $\mathrm{T}$ cell subset percentages, or surface markers of activation and senescence, and either clinical measures of motor and cognitive function or equivalent daily levodopa dose.

CMV IgG seropositivity was not significantly different between PD cases (19/41) and controls (25/41) $(p=0.18)$. Nonetheless, given the previously described association between CMV exposure and CD8 immunosenescence, we explored this relationship further. As anticipated, CD8+ senescence markers were elevated in CMV-positive versus 
CMV-negative subjects overall, including CD57 expression (ANOVA with age as covariate, $F=4.66, \quad p=0.03$ ), CD28 ${ }_{\mathrm{lo}}$ CD57 ${ }_{\text {hi }}$ cells (\% of lymphocytes, $F=18.75, p<0.001$ ) and TEMRA cells (\% of lymphocytes, $F=12.71, p=0.001$ ). However, this effect was more apparent for controls than for PD patients, with significantly higher CD57 expression $(p=0.017)$ and $\mathrm{CD} 28_{\mathrm{lo}} \mathrm{CD} 57_{\mathrm{hi}}$ cells (\% of lymphocytes, $p=0.028)$ in controls versus $\mathrm{PD}$ cases in the CMV-positive group (Fig. 2).

\section{Discussion}

This study demonstrates for the first time that the peripheral immune profile in PD is distinctly atypical for a more elderly population, with a lack of the CD8+ T cell replicative senescence which characterises normal ageing. Although other authors have reported phenotypic alterations in the $\mathrm{T}$ lymphocyte population in $\mathrm{PD}$, these alterations have mainly been restricted to $\mathrm{CD} 4+$ cell subsets with conflicting findings $[9,32,33]$ and we found no changes in the CD4+ $\mathrm{T}$ cell pool in this study. No previous studies have specifically explored markers of $\mathrm{T}$ cell replicative senescence in PD. CMV infection has been strongly implicated in CD8+ replicative senescence [18], but this does not appear to be confounding our observations, with similar levels of CMV IgG positivity in both patient and control groups. Instead, the senescent shift typically induced by chronic latent CMV infection is not observed in this PD cohort. This is an intriguing finding, raising the possibility that there are inherent differences in the adaptive immune response to chronic viral infections in PD. We hypothesise that these differences may contribute to a more active $\mathrm{T}$ cell-mediated immune response to PD-relevant antigens such as alpha synuclein, leading in turn to an exaggerated neuroinflammatory response which may contribute to the neuropathology of PD.

In keeping with this hypothesis, there is well-established evidence from genetic studies of an immune-mediated susceptibility to PD, with association between the HLA locus, which is critical in antigen recognition, and PD risk
$[14,34]$, as well as more widespread genomic associations in loci affecting $\mathrm{T}$ cell regulation and function $[35,36]$. Furthermore, specific $\mathrm{T}$ cell responses to epitopes of alpha synuclein have recently been described at a higher frequency in PD patients than controls by Sulzer and colleagues [11] and were closely associated with possession of known PD risk alleles at the HLA locus. In addition, alpha synuclein peptides have been shown to bind to these HLA 'risk variant' molecules in vitro, thus revealing a potential functional mechanism through which the well-described HLA association may contribute to the development of PD. Whilst the authors of this work highlighted the importance of the Th2-type CD4+ cell-mediated response observed in their experiments, they also found evidence of a significant CD8+-mediated response when stimulating cells with shorter alpha synuclein peptides, and in fact, the strongest association between alpha synuclein-specific T cell responses and HLA was seen for the MHC class I allele HLA A*11.02, thus underlining the relevance of the $\mathrm{CD} 8$ (MHC class 1 restricted) response [11]. The latter would be in keeping with our observations that PD-associated immunophenotypic changes in our cohort were within the CD8+ population. Other authors have similarly shown an elevated $\mathrm{CD} 8+\mathrm{T}$ cell response to alpha synuclein peptides and herpes simplex virus peptides in $\mathrm{PD}$ versus controls [37].

The mechanism by which alterations in peripheral CD8 + T cell function and CNS pathology interact in PD is still not fully elucidated. However, it is now clear that there is an abundance of $\mathrm{T}$ lymphocytes within the meninges which keep the brain under immune surveillance and which drain, together with CNS antigens, via the CNS lymphatic system to the local lymph nodes [38]. These meningeal $\mathrm{T}$ cells may be activated by 'alarm signals' released into the CSF by degenerating CNS neurones [39] and in turn produce inflammatory cytokines which can diffuse into the brain parenchyma and lead to further activation of already 'primed' microglia [40] and/ or impact directly on neuronal function [41].
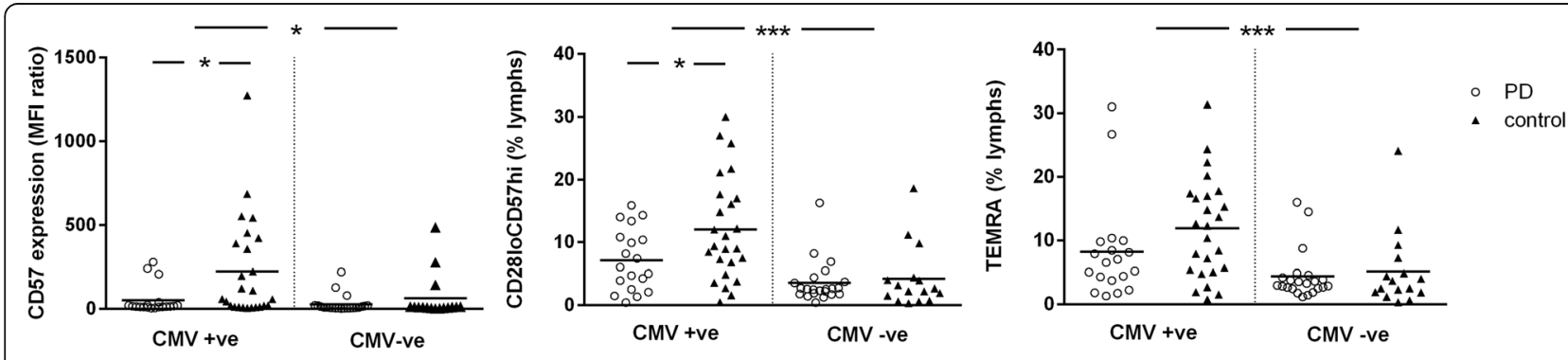

Fig. 2 CD8+ senescence markers in CMV-positive versus CMV-negative subjects. The figure shows CD57 expression on CD8+ lymphocytes (median fluorescence intensity (MFI) ratio versus unstained lymphocytes), CD8+ CD28 ${ }_{\mathrm{lo}} \mathrm{CD} 57_{\mathrm{hi}}$ cells (percentage of lymphocytes) and TEMRA cells (percentage of lymphocytes) in PD versus age-matched controls stratified by CMV seropositivity. Horizontal lines denote means; ${ }^{*} p<0.05$ and ${ }^{* * *} p \leq 0.001$ 
Furthermore, the presence of CD8+ cells within the brain parenchyma in postmortem tissue from PD patients raises the possibility of direct interaction with neurones presenting relevant antigen in the context of MHC class 1, with consequent cytotoxic effects [12].

In this study, we adopted a hypothesis-driven approach and so restricted our $\mathrm{T}$ cell phenotyping to specifically explore cell subsets and markers relevant to activation and replicative senescence. A consequent limitation of the study is that we were not able to fully characterise the $\mathrm{T}$ cell population in our cohort, nor assess changes in $\mathrm{T}$ regulatory cells, which have been reported to be reduced in both number, and functional ability to suppress effector T cells in PD patients [9]. Another potential limitation of our study is that the majority of our patients were taking dopaminergic medication, which has been implicated as a potential confounding factor in alterations in lymphocyte populations in PD cohorts [33]. In particular, in vitro data indicates that dopamine is an activator of effector $\mathrm{T}$ cells and an inhibitor of regulatory $\mathrm{T}$ cells [42]. However, studies specifically comparing medicated and unmedicated PD patients have found no relationship between levodopa treatment and changes in T cell subsets [32]. Similarly, we found no associations between $\mathrm{T}$ cell phenotypes or surface marker expression and equivalent levodopa dose in our patient cohort suggesting that medication was not a significant factor driving the observed reduction in markers of CD8 replicative senescence.

Although we found clear differences in $\mathrm{T}$ cell senescence markers between patient and control groups, we were not able to demonstrate a relationship between these markers and dementia risk status or clinical measures of disease severity within the PD group. This may be because the observed immunophenotypic differences are most relevant to the earliest stages of the disease, impacting on susceptibility but not on the rate of progression. However, the power of our study to detect differences between dementia risk subgroups was likely suboptimal given the size of our cohort. In terms of measures of disease severity, the spread across the group was relatively minimal (Table 1 ) which consequently limited our ability to explore correlations with disease stage. Further studies exploring these markers both across a range of disease stages, and longitudinally in individual patients, would be of interest.

\section{Conclusions}

Our data reveal that there is a reduction in age-associated replicative senescence of CD8+ $\mathrm{T}$ cells in PD patients compared with strictly age-matched controls. Hence, whilst immunosenescence may be detrimental in terms of increased susceptibility to infections and cancers with increasing age, it may provide a degree of protection against age-related neurodegenerative disorders such as PD, through limiting immune activation to aberrant peptides associated with these diseases. On a practical level, this work suggests that the CD8+ CD28 ${ }_{\mathrm{lo}} \mathrm{CD} 57_{\mathrm{hi}}$ immunophenotype warrants further evaluation as a biomarker in PD, which could be relevant for patient stratification for clinical trials of immunomodulating therapies. Furthermore, whilst immunomodulatory strategies targeting the CD4 population are being developed [43], the CD8 population may also warrant consideration as a target for immune therapies in PD.

\section{Abbreviations}

ACE-R: Addenbrooke's Cognitive Examination-Revised; ANOVA: Analysis of variance; CMV: Cytomegalovirus; CSF: Cerebrospinal fluid;

EDTA: Ethylenediaminetetraacetic acid; HLA: Human leucocyte antigen; MAPT: Microtubule-associated protein tau; MDS-UPDRS: Movement Disorder Society Unified Parkinson's Disease Rating Scale; MFI: Median fluorescence intensity; PBMC: Peripheral blood mononuclear cell; PD: Parkinson's disease; RTE: Recent thymic emigrant; SD: Standard deviation; TEMRA: Terminally differentiated effector memory CD45RA+ cells

\section{Acknowledgements}

We gratefully acknowledge the participation of all our patient volunteers and NIHR Cambridge BioResource volunteers. We thank the Cambridge BioResource staff for their help with volunteer recruitment.

We thank members of the Cambridge BioResource SAB and Management Committee for their support of our study. We also acknowledge the support of the Cambridge NIHR BRC Cell Phenotyping Hub.

\section{Funding}

Grant funding from the Academy of Medical Sciences, UK, the Rosetrees Trust, the Stevenage Biosciences Catalyst and Addenbrooke's Charitable Trust contributed to this work. The research was also supported by the NIHR Cambridge Biomedical Research Centre (Cambridge University Hospitals NHS Trust/University of Cambridge). C. H. Williams-Gray is supported by a fellowship from the Medical Research Council. R. S. Wijeyekoon was supported by a fellowship from Addenbrooke's Charitable Trust. K. M. Scott and J. L. Jones are supported by fellowships from the Wellcome Trust. R. A. Barker is supported by the Wellcome-MRC Cambridge Stem Cell Institute. The funding bodies had no role in the design of the study; the collection, analysis and interpretation of data; or the writing of the manuscript.

\section{Availability of data and materials}

Datasets used during the current study are available from the corresponding author on reasonable request. Access to Cambridge BioResource volunteers and their data and samples is governed by the Cambridge BioResource SAB. Documents describing access arrangements and contact details are available at http://www.cambridgebioresource.org.uk/.

\section{Authors' contributions}

CHW-G contributed to the study design, acquisition of data, analysis and interpretation of data and drafting of the manuscript. RW contributed to the acquisition of data and critical revision of the manuscript. KMS contributed to the acquisition of data and critical revision of the manuscript. SH contributed to the acquisition of data and critical revision of the manuscript. RAB contributed to the study design and supervision and critical revision of the manuscript. $\amalg J$ contributed to the supervision of study, study design, interpretation of data and critical revision of the manuscript. All authors read and approved the final manuscript.

\section{Ethics approval and consent to participate}

This study was approved by the East of England-Cambridge Central Research Ethics Committee (ref 03/303). All participants provided written informed consent 


\section{Publisher's Note}

Springer Nature remains neutral with regard to jurisdictional claims in published maps and institutional affiliations.

\section{Author details}

'John Van Geest Centre for Brain Repair, Department of Clinical

Neurosciences, University of Cambridge, Forvie Site, Cambridge CB2 OPY, UK.

${ }^{2}$ Neurology Unit, Department of Clinical Neurosciences, University of

Cambridge, Cambridge, UK.

Received: 14 March 2018 Accepted: 16 May 2018

Published online: 28 May 2018

\section{References}

1. Hirsch EC, Hunot S. Neuroinflammation in Parkinson's disease: a target for neuroprotection? Lancet Neurol. 2009;8:382-97.

2. Collins LM, Toulouse A, Connor TJ, Nolan YM. Contributions of central and systemic inflammation to the pathophysiology of Parkinson's disease. Neuropharmacology. 2012;62:2154-68.

3. Gerhard A, Pavese N, Hotton G, Turkheimer F, Es M, Hammers A, Eggert K, Oertel W, Banati RB, Brooks DJ. In vivo imaging of microglial activation with [11C](R)-PK11195 PET in idiopathic Parkinson's disease. Neurobiol Dis. 2006; 21:404-12.

4. Edison P, Ahmed I, Fan Z, Hinz R, Gelosa G, Ray Chaudhuri K, Walker Z, Turkheimer FE, Brooks DJ. Microglia, amyloid, and glucose metabolism in Parkinson's disease with and without dementia. Neuropsychopharmacology. 2013:38:938-49.

5. Ouchi Y, Yoshikawa E, Sekine Y, Futatsubashi M, Kanno T, Ogusu T, Torizuka T. Microglial activation and dopamine terminal loss in early Parkinson's disease. Ann Neurol. 2005;57:168-75.

6. Zhang J, Sokal I, Peskind ER, Quinn JF, Jankovic J, Kenney C, Chung KA, Millard SP, Nutt JG, Montine TJ. CSF multianalyte profile distinguishes Alzheimer and Parkinson diseases. Am J Clin Pathol. 2008:129:526-9.

7. Yu SY, Zuo LJ, Wang F, Chen ZJ, Hu Y, Wang YJ, Wang XM, Zhang W. Potential biomarkers relating pathological proteins, neuroinflammatory factors and free radicals in PD patients with cognitive impairment: a crosssectional study. BMC Neurol. 2014:14:113.

8. Grozdanov V, Bliederhaeuser C, Ruf WP, Roth V, Fundel-Clemens K, Zondler L, Brenner D, Martin-Villalba A, Hengerer B, Kassubek J, et al. Inflammatory dysregulation of blood monocytes in Parkinson's disease patients. Acta Neuropathol. 2014;128:651-63.

9. Saunders JA, Estes KA, Kosloski LM, Allen HE, Dempsey KM, Torres-Russotto DR, Meza JL, Santamaria PM, Bertoni JM, Murman DL, et al. CD4+ regulatory and effector/memory T cell subsets profile motor dysfunction in Parkinson's disease. J Neurolmmune Pharmacol. 2012;7:927-38.

10. Stevens $\mathrm{CH}$, Rowe D, Morel-Kopp MC, Orr C, Russell T, Ranola M, Ward C Halliday GM. Reduced T helper and B lymphocytes in Parkinson's disease. J Neuroimmunol. 2012;252:95-9.

11. Sulzer D, Alcalay RN, Garretti F, Cote L, Kanter E, Agin-Liebes J, Liong C, McMurtrey C, Hildebrand WH, Mao X, et al. T cells from patients with Parkinson's disease recognize alpha-synuclein peptides. Nature. 2017;546:656-61.

12. Brochard V, Combadiere B, Prigent A, Laouar Y, Perrin A, Beray-Berthat V, Bonduelle $\mathrm{O}$, Alvarez-Fischer D, Callebert J, Launay JM, et al. Infiltration of CD4+ lymphocytes into the brain contributes to neurodegeneration in a mouse model of Parkinson disease. J Clin Invest. 2009:119:182-92.

13. Gao HM, Zhang F, Zhou H, Kam W, Wilson B, Hong JS. Neuroinflammation and alpha-synuclein dysfunction potentiate each other, driving chronic progression of neurodegeneration in a mouse model of Parkinson's disease. Environ Health Perspect. 2011:119:807-14.

14. Saiki M, Baker A, Williams-Gray CH, Foltynie T, Goodman RS, Taylor CJ, Compston DA, Barker RA, Sawcer SJ, Goris A. Association of the human leucocyte antigen region with susceptibility to Parkinson's disease. J Neurol Neurosurg Psychiatry. 2010;81:890-1.

15. Nalls MA, Pankratz N, Lill CM, Do CB, Hernandez DG, Saad M, DeStefano AL, Kara E, Bras J, Sharma M, et al. Large-scale meta-analysis of genome-wide association data identifies six new risk loci for Parkinson's disease. Nat Genet. 2014;46:989-93

16. Williams-Gray CH, Wijeyekoon R, Yarnall AJ, Lawson RA, Breen DP, Evans JR, Cummins GA, Duncan GW, Khoo TK, Burn DJ, et al. Serum immune markers and disease progression in an incident Parkinson's disease cohort (ICICLE-PD). Mov Disord. 2016;31:995-1003.
17. Chou JP, Effros RB. T cell replicative senescence in human aging. Curr Pharm Des. 2013;19:1680-98.

18. Pawelec $G$, Larbi A, Derhovanessian E. Senescence of the human immune system. J Comp Pathol. 2010;142(Suppl 1):S39-44.

19. Larbi A, Fulop T. From "truly naïve" to "exhausted senescent" $T$ cells: when markers predict functionality. Cytometry Part A. 2014:85:25-35.

20. Strioga M, Pasukoniene V, Characiejus D. CD8+ CD28- and CD8+ CD57+ T cells and their role in health and disease. Immunology. 2011;134:17-32.

21. Tarazona R, DelaRosa O, Alonso C, Ostos B, Espejo J, Pena J, Solana R. Increased expression of NK cell markers on T lymphocytes in aging and chronic activation of the immune system reflects the accumulation of effector/senescent T cells. Mech Ageing Dev. 2000;121:77-88.

22. Le Priol Y, Puthier D, Lecureuil C, Combadiere C, Debre P, Nguyen C, Combadiere B. High cytotoxic and specific migratory potencies of senescent CD8+ CD57+ cells in HIV-infected and uninfected individuals. J Immunol. 2006;177:5145-54.

23. Northfield JW, Loo CP, Barbour JD, Spotts G, Hecht FM, Klenerman P, Nixon DF, Michaelsson J. Human immunodeficiency virus type 1 (HIV-1)-specific CD8+ T(EMRA) cells in early infection are linked to control of HIV-1 viremia and predict the subsequent viral load set point. J Virol. 2007;81:5759-65.

24. Ferguson FG, Wikby A, Maxson P, Olsson J, Johansson B. Immune parameters in a longitudinal study of a very old population of Swedish people: a comparison between survivors and nonsurvivors. J Gerontol A Biol Sci Med Sci. 1995;50:B378-82

25. Khan N, Shariff N, Cobbold M, Bruton R, Ainsworth JA, Sinclair AJ, Nayak L, Moss PA. Cytomegalovirus seropositivity drives the CD8 T cell repertoire toward greater clonality in healthy elderly individuals. J Immunol. 2002;169: 1984-92.

26. Hadrup SR, Strindhall J, Kollgaard T, Seremet T, Johansson B, Pawelec G, thor Straten P, Wikby A. Longitudinal studies of clonally expanded CD8 T cells reveal a repertoire shrinkage predicting mortality and an increased number of dysfunctional cytomegalovirus-specific T cells in the very elderly. J Immunol. 2006;176:2645-53.

27. Weng NP, Akbar AN, Goronzy J. CD28(-) T cells: their role in the ageassociated decline of immune function. Trends Immunol. 2009;30:306-12.

28. Perry VH. Contribution of systemic inflammation to chronic neurodegeneration. Acta Neuropathol. 2010;120:277-86.

29. Gibb WR, Lees AJ. The relevance of the Lewy body to the pathogenesis of idiopathic Parkinson's disease. J Neurol Neurosurg Psychiatry. 1988;51:745-52.

30. Tomlinson CL, Stowe R, Patel S, Rick C, Gray R, Clarke CE. Systematic review of levodopa dose equivalency reporting in Parkinson's disease. Mov Disord. 2010;25:2649-53.

31. Williams-Gray CH, Evans JR, Goris A, Foltynie T, Ban M, Robbins TW, Brayne C, Kolachana BS, Weinberger DR, Sawcer SJ, Barker RA. The distinct cognitive syndromes of Parkinson's disease: 5 year follow-up of the CamPalGN cohort. Brain. 2009;132:2958-69.

32. Bas J, Calopa M, Mestre M, Mollevi DG, Cutillas B, Ambrosio S, Buendia E. Lymphocyte populations in Parkinson's disease and in rat models of parkinsonism. J Neuroimmunol. 2001;113:146-52.

33. Baba Y, Kuroiwa A, Uitti RJ, Wszolek ZK, Yamada T. Alterations of T-lymphocyte populations in Parkinson disease. Parkinsonism Relat Disord. 2005;11:493-8.

34. International Parkinson Disease Genomics Consortium, Nalls MA, Plagnol V, Hernandez DG, Sharma M, Sheerin UM, Saad M, Simon-Sanchez J, Schulte C, Lesage $S$, et al. Imputation of sequence variants for identification of genetic risks for Parkinson's disease: a meta-analysis of genome-wide association studies. Lancet. 2011:377:641-9.

35. Holmans $P$, Moskvina V, Jones $L$, Sharma M, The International Parkinson's Disease Genomics C, Vedernikov A, Buchel F, Sadd M, Bras JM, Bettella F, et al. A pathway-based analysis provides additional support for an immunerelated genetic susceptibility to Parkinson's disease. Hum Mol Genet. 2013; 22:1039-49.

36. Gagliano SA, Pouget JG, Hardy J, Knight J, Barnes MR, Ryten M, Weale ME. Genomics implicates adaptive and innate immunity in Alzheimer's and Parkinson's diseases. Ann Clin Transl Neurol. 2016;3:924-33.

37. Caggiu E, Paulus K, Galleri G, Arru G, Manetti R, Sechi GP, Sechi LA. Homologous HSV1 and alpha-synuclein peptides stimulate a T cell response in Parkinson's disease. J Neuroimmunol. 2017;310:26-31.

38. Louveau A, Smirnov I, Keyes TJ, Eccles JD, Rouhani SJ, Peske JD, Derecki NC, Castle D, Mandell JW, Lee KS, et al. Structural and functional features of central nervous system lymphatic vessels. Nature. 2015;523:337-41. 
39. Gadani SP, Smirnov I, Smith AT, Overall CC, Kipnis J. Characterization of meningeal type 2 innate lymphocytes and their response to CNS injury. J Exp Med. 2017;214:285-96.

40. Perry VH, Holmes C. Microglial priming in neurodegenerative disease. Nat Rev Neurol. 2014;10:217-24.

41. Filiano AJ, Xu Y, Tustison NJ, Marsh RL, Baker W, Smirnov I, Overall CC, Gadani SP, Turner SD, Weng Z, et al. Unexpected role of interferon- $\gamma$ in regulating neuronal connectivity and social behaviour. Nature. 2016;535:425.

42. Levite M. Dopamine and T cells: dopamine receptors and potent effects on $T$ cells, dopamine production in T cells, and abnormalities in the dopaminergic system in T cells in autoimmune, neurological and psychiatric diseases. Acta Physiol (Oxf). 2016;216:42-89.

43. Gendelman HE, Zhang Y, Santamaria P, Olson KE, Schutt CR, Bhatti D, Shetty $B L D, L$ Y Y, Estes KA, Standaert DG, et al. Evaluation of the safety and immunomodulatory effects of sargramostim in a randomized, double-blind phase 1 clinical Parkinson's disease trial. NPJ Parkinsons Dis. 2017;3:10.

Ready to submit your research? Choose BMC and benefit from:

- fast, convenient online submission

- thorough peer review by experienced researchers in your field

- rapid publication on acceptance

- support for research data, including large and complex data types

- gold Open Access which fosters wider collaboration and increased citations

- maximum visibility for your research: over $100 \mathrm{M}$ website views per year

At BMC, research is always in progress.

Learn more biomedcentral.com/submissions 